Proc. 15th Int. Conference on Defects Recognition, Imaging and Physics in Semiconductors, Warsaw, Poland 2013

\title{
Characterisation of (100) GaSb Passivated Surface Using Next Generation 3D Digital Microscopy
}

\author{
E. PAPIS-POLAKOWSKA ${ }^{a, *}$, E. LEONHARDT ${ }^{b}$ AND J. KANIEWSKI ${ }^{a}$ \\ ${ }^{a}$ Institute of Electron Technology, al. Lotników 32/46, 02-668 Warszawa, Poland \\ ${ }^{b}$ HIROX EUROPE, Jyfel, 9 rue des Gantries, F-69130 Ecully, France
}

(100) GaSb surface was modified by self-assembled superficial layer of organic molecules by wet chemical process. Hexadecanethiol (HDT) was the choice as modifier. The treated GaSb surface, whose quality affects the morphology of the resulting modified GaSb, was investigated by 3D digital microscopy. The structural study were carried out quickly, non-destructively and comprehensively with using the next generation 3D HIROX KH- 8700 Digital Microscope.

DOI: 10.12693/APhysPolA.125.1052

PACS: 07.60.Pb, 64.75.Yz, 81.65.Rv

\section{Introduction}

The passivation has been the subject of intensive studies on micro- and optoelectronics semiconductor devices, especially on antimonides-based infrared photodetectors. High surface state densities, surface Fermi level pinning and a residual oxide layer on the surface are the common problems of all III-V semiconductors. These phenomena have a negative effect on the work of many devices, and stand in the way of complete application potentials of these materials. To eliminate the undesirable effect of the surface on device properties, passivation treatment is being actively developed in technology. This is especially true for GaSb-based materials, which are well recognized for their potential in modern infrared optoelectronics.

$\mathrm{GaSb}$ is known to be highly reactive and easy oxidizes under atmospheric conditions forming an oxide layer that is not self limiting, stable and abrupt. In search for appropriate passivating coatings the GaSb-based surface treatment in sulfur containing solutions (chalcogen-based passivation) has received much attention [1]. The new passivation method, promising especially for type-II superlattice InAs/GaSb structure (T2SLs) is an organic passivation by using organic sulfur sources, like thiols or thioacetamide $[2,3]$. T2SLs is an attractive material for a mid-, long- and very long wavelength modern photonic devices, in particular for the third generation infrared detectors [4].

The comparative investigations of inorganic and organic sulfur sources confirm the hypothesis that organic passivation is a good method both for the effective performance improvement of modern devices and for biofunctionalization of surface, forming the self-assembled monolayers (SAMs) (Fig. 1). It is expected to explain the unsolved T2SLs passivation problem and create the new directions for the next generation diagnostic biosensor systems. While a number of studies have been performed in order to present thiols on GaAs [6] and InP [7] surfaces, little is known on the thiols passivation of GaSb-based devices. (a)

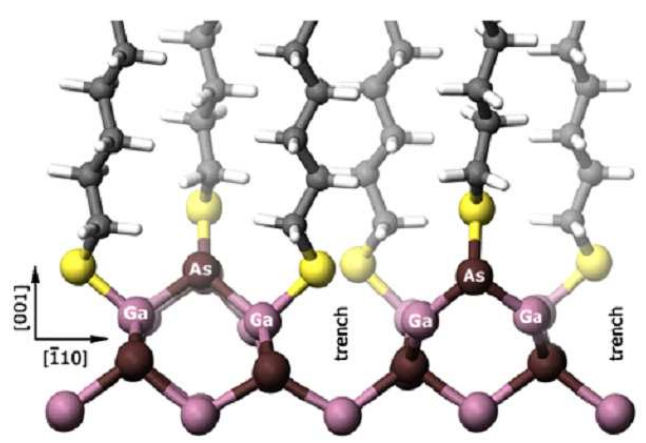

(b)

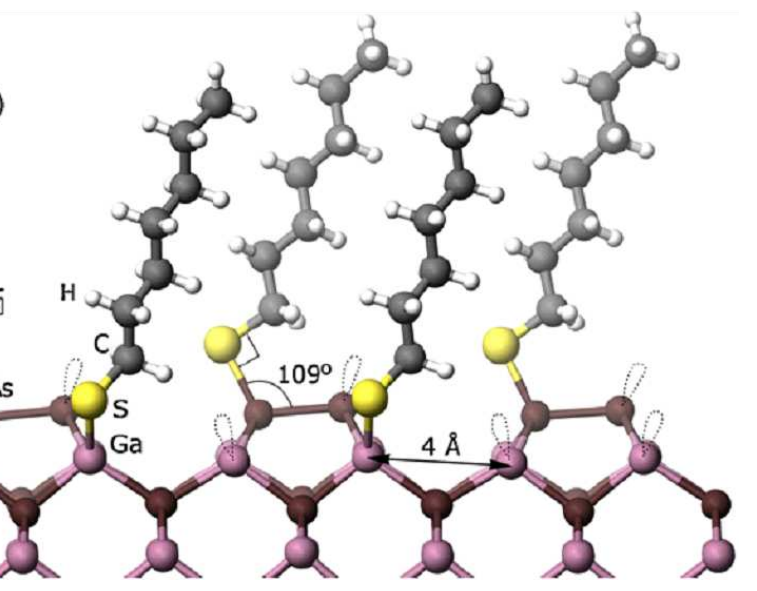

Fig. 1. Front (a) and side (b) views of the proposed structure for thiols SAMs on (001) GaAs [5].

**corresponding author; e/mail: papis@ite.waw.pl

On the other hand, 3D imaging technique is important for the micro- and nanotechnology, especially for surface characterisation, defects recognition, the local structures 
of devices and bonding quality control. 3D imaging and characterising of the surfaces at the micro- and nanometer scale are also critical to the final production process of modern devices.

In this work, the results of the formation of SAMs from hexadecanethiol (HDT) on (100) GaSb surface have been presented. The surface morphology after passivation was examined using 3D microscopy technique.

\section{Experimental}

(100) oriented undoped GaSb samples were used in these experiments. Prior to the chemical treatment in thiols solution they were cleaned in degreasing in hot organic solvents terminated by cold isopropanol rinse and etched sequentially in $30 \mathrm{HCl}+1 \mathrm{HNO}_{3}$ at $T=5^{\circ} \mathrm{C}$ for $t=20 \mathrm{~s}$ and $1 \mathrm{HCl}+6 \mathrm{H}_{2} \mathrm{O}$ at RT for $60 \mathrm{~s}$. In thiols-based treatment hexadecanethiol (HDT) has been used. The GaSb samples were immersed in $2 \mathrm{mM}$ solution of HDT in ethanol and were left there for $24 \mathrm{~h}$ at RT. Then the samples were rinsed with ethanol and dried with dry $\mathrm{N}_{2}$.

The images of thiols deposited on GaSb surface were obtained by using 3D Digital KH-8700 microscope - the new product of HIROX company. Historically, HIROX founded 1978 in Tokyo - a famous producer of modern optical lenses - invented the first video microscope in 1985 and continues to develop the most innovative optics such as the Hirox 3D Rotary Head and the HIROX Triple Objective Revolver Lens. Most of all, HIROX is a pioneer and a world leader in the high-end 3D digital microscopy.

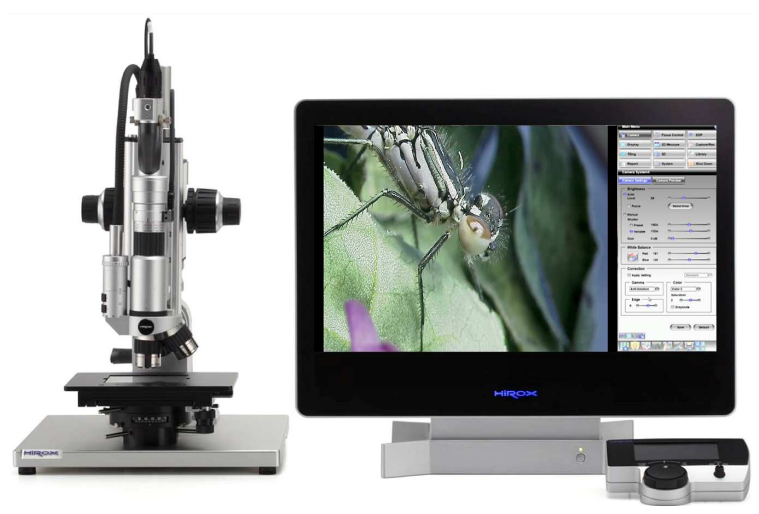

Fig. 2. HIROX KH-8700 Digital Microscope with revolver zoom lens.

The HIROX KH-8700 Digital Microscope (Fig. 2) is the next generation system for the high quality triple optical study - high definition inspection, high precision measurement and high speed 3D profiling. This model of microscope - as all HIROX products - is fast, easy and high quality. It is fast, because the whole new HIROX platform delivers fast operation and processor speeds, easy, because the premier choice in user friendly software, a digital microscope has never been easier to operate and high quality, because images saved and taken with the KH-8700 are delivered through ultra-fine detail. Thanks to the new 64 bits processor, both $2 \mathrm{D}$ and $3 \mathrm{D}$ measurements have never been faster.
The full HD camera with HDMI output redefines the highest image quality standard. The new auto count feature, as well as the roughness measurements, boosting optical magnification up to 10,000 times bigger on a screen, makes the KH-8700 model the perfect all-round inspection and measurement tool for a huge amount of applications. The 21.5" Full HD LCD (High Definition Liquid Crystal Display) monitor $(1920 \times 1080$ pixels $)$ integrated to KH- 8700 has one of the top grade high intensity pixel reproduction.

For the first time ever in digital microscopy, the central control unit (CCU) (Genex), combines a high sensitivity compact charge coupled devices (CCD) camera operating in a 32 bit image with the high resolution at $1200 \times 1600$ pixels on "Live Image". The new high intensity light-emitting diode (LED) light source provides $5700 \mathrm{~K}$ temperature, which closely portrays day light colour temperature $(5460 \mathrm{~K})$ to re-produce true sample colour image as well as full illumination immediately with no warm up time. The fast 3D profiling and measurement function enables multi-focusing by extending the depth of field. For the highest precision, the system of $50 \mathrm{~nm}$ motorized $Z$-axis and very fine motorized $X Y$ stage was used and consequently allows $2 \mathrm{D} \& 3 \mathrm{D}$ stitching up to 225 million pixels.

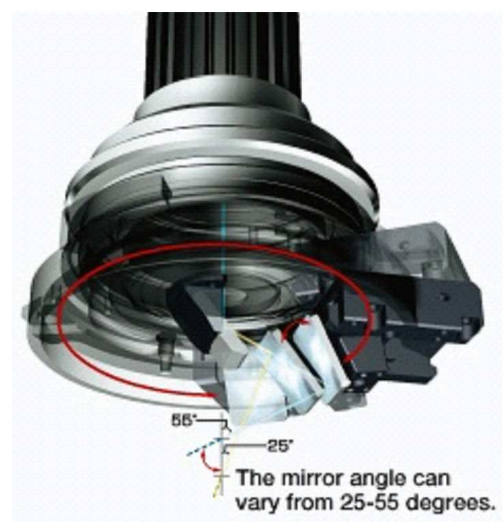

Fig. 3. Patented HIROX motorized 3D Rotary Head with variable viewing angle.

Attaching the rotary-head adapter enables $360^{\circ} 3 \mathrm{D}$ image detection and makes an observation more precise and attractive (Fig. 3). The HIROX KH-8700 is a real technological hit, desired both by industry and science. Recently, the BBC has selected the HIROX KH-8700 Digital Microscope to film several amazing nature documentaries [8]. Additionally, the thickness of the superficial layer on (100) GaSb surface were examined by using variable angle spectroscopic ellipsometry (VASE, J.A. Woollam).

\section{Results}

HIROX KH-8700 3D Digital Microscope was used for surface investigation and inspection of (100) GaSb 
treated in $2 \mathrm{mM} \mathrm{HDT}-\mathrm{C}_{2} \mathrm{H}_{5} \mathrm{OH}$ solution. The images of (100) GaSb surface exposed to HDT deposition have been presented in Figs. 4-11.

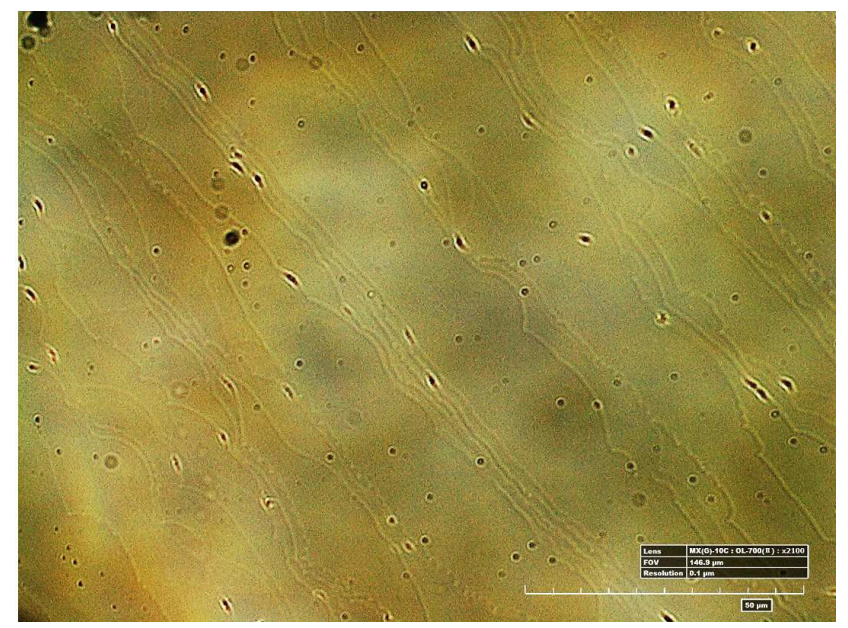

Fig. 4. The image of (100) GaSb surface passivated in $2 \mathrm{mM}$ HDT $-\mathrm{C}_{2} \mathrm{H}_{5} \mathrm{OH}$ with FOV $146.9 \mu \mathrm{m}$, resolution $0.1 \mu \mathrm{m}$ and magnification $2100 \times$.

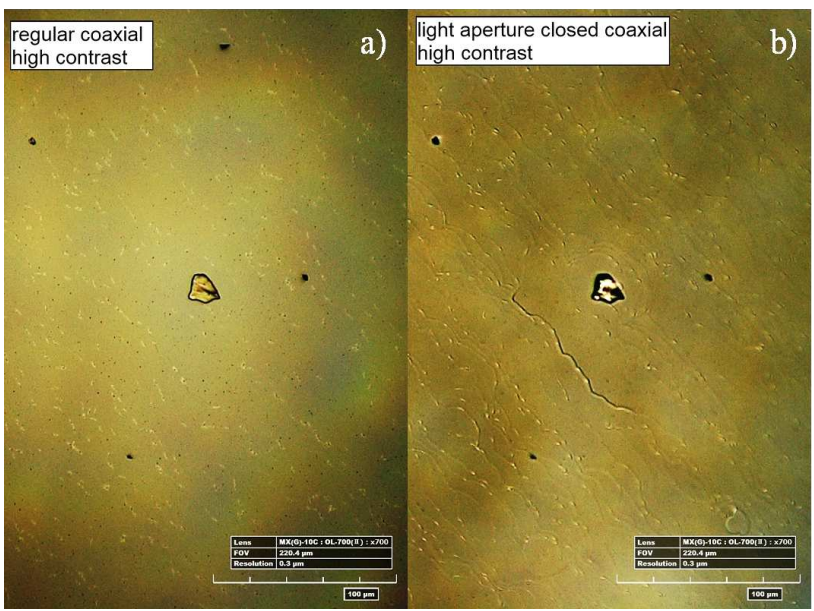

Fig. 5. The image of (100) GaSb surface passivated in $2 \mathrm{mM}$ HDT $-\mathrm{C}_{2} \mathrm{H}_{5} \mathrm{OH}$ with FOV $220.4 \mu \mathrm{m}$, resolution $0.3 \mu \mathrm{m}$ and magnification $700 \times$ : (a) with regular coaxial high contrast, (b) high aperture closed coaxial high contrast.

As can be observed in Figs. 4-6, a superficial layer is present on (100) GaSb surface treated in HDT solution. The additional spectroscopic ellipsometry measurements indicate that this thiols superficial layer is thin $(d=8 \mathrm{~nm})$ and has dielectric properties $\left(\varepsilon_{2}=0\right)$.

It is worth to mention that regularly arranged thiols islands are presented as well (Fig. 7).

The possibilities and technical options of microscope allowed to observe and characterise the thiols islands (Figs. 8-11). The images were obtained for fields of view $(\mathrm{FOV})=53.5,146.9$, and $220.4 \mu \mathrm{m}$, by using several objectives which gave the magnification and resolution

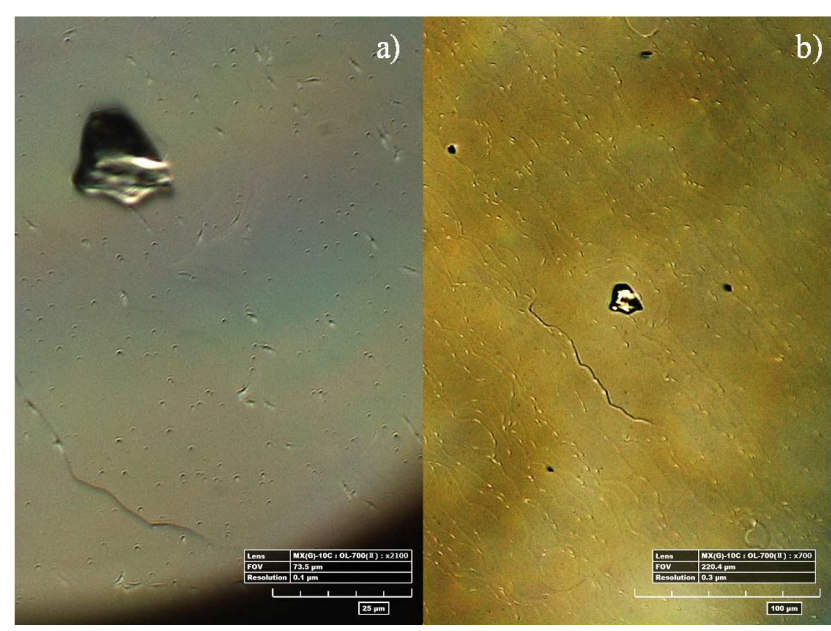

Fig. 6. The image of (100) GaSb surface passivated in $2 \mathrm{mM}$ HDT $-\mathrm{C}_{2} \mathrm{H}_{5} \mathrm{OH}$ : (a) with FOV $73.5 \mu \mathrm{m}$, resolution $0.1 \mu \mathrm{m}$ and magnification $2100 \times$, (b) with FOV $220.4 \mu \mathrm{m}$, resolution $0.3 \mu \mathrm{m}$ and magnification $700 \times$.

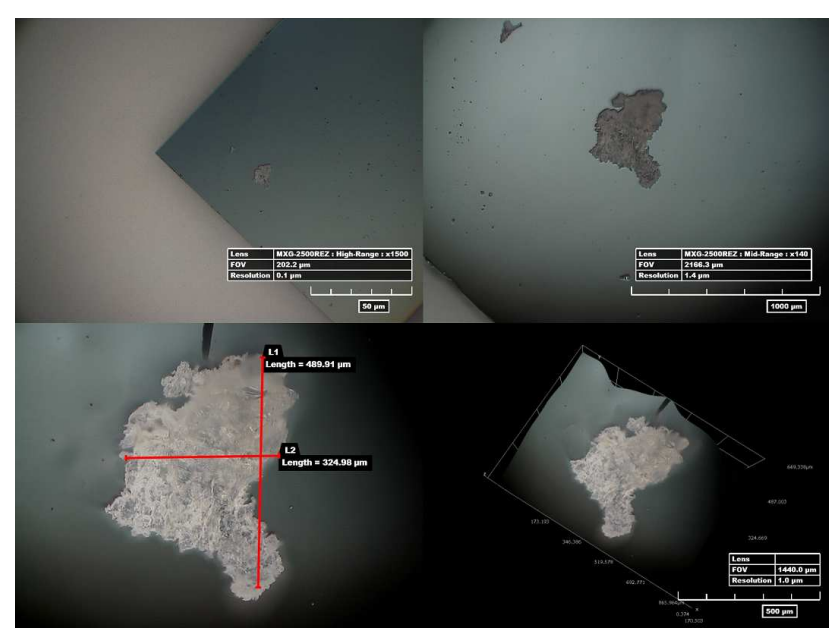

Fig. 7. HDT island on (100) GaSb surface passivated in $2 \mathrm{mM} \mathrm{HDT}-\mathrm{C}_{2} \mathrm{H}_{5} \mathrm{OH}$ with different $\mathrm{FOV}$, resolution and magnification.

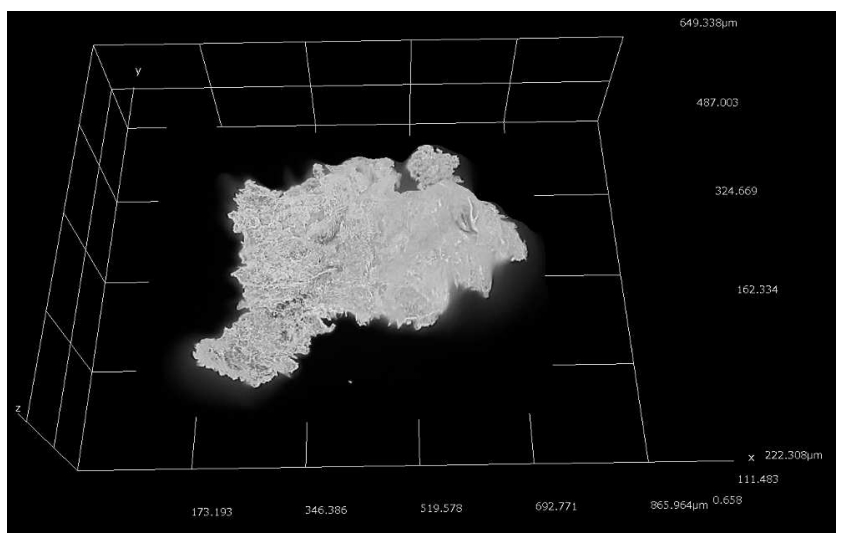

Fig. 8. 3D imaging of HDT island on (100) GaSb surface passivated in $2 \mathrm{mM} \mathrm{HDT}-\mathrm{C}_{2} \mathrm{H}_{5} \mathrm{OH}$. 


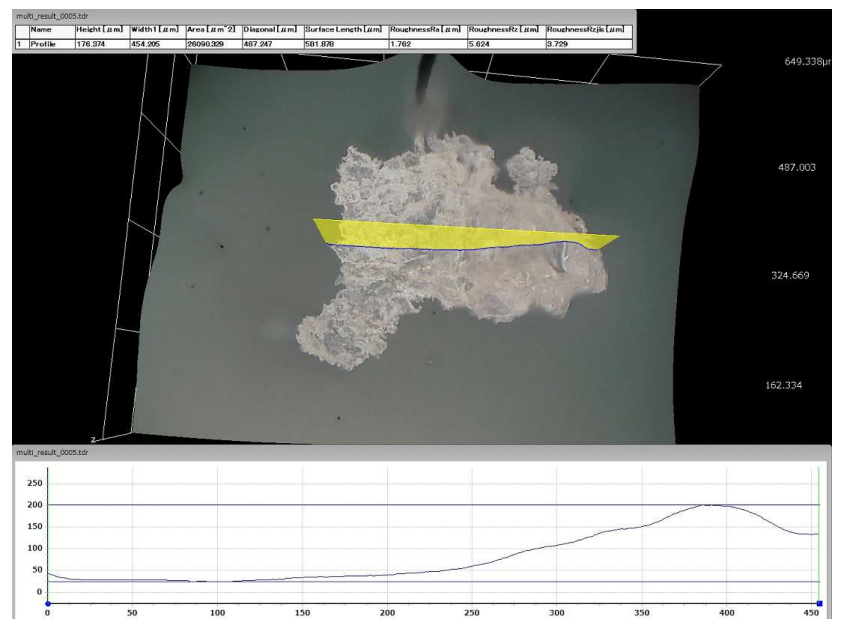

Fig. 9. 3D imaging and 3D profile of HDT island on (100) GaSb surface passivated in $2 \mathrm{mM}$ HDT $-\mathrm{C}_{2} \mathrm{H}_{5} \mathrm{OH}$.

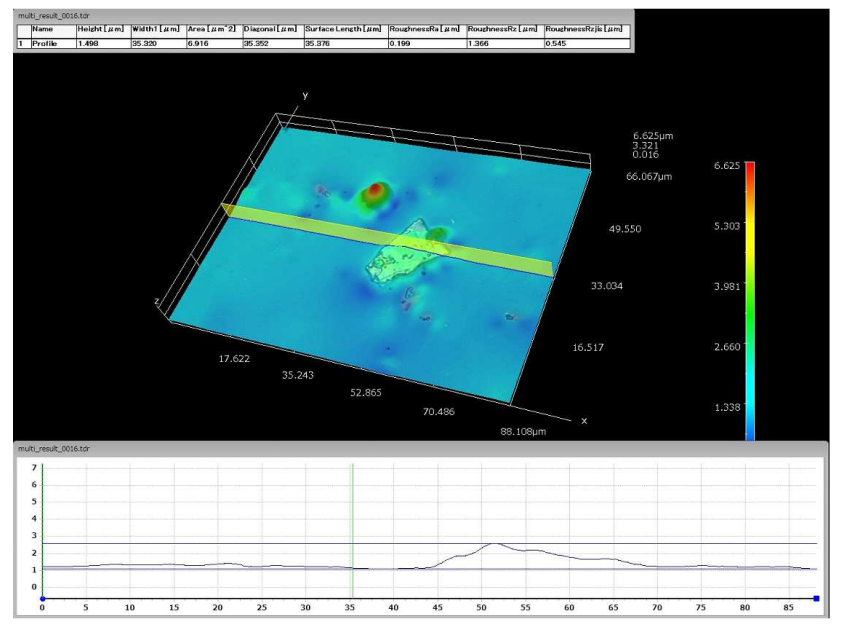

Fig. 10. 3D profile (approximately $1.5 \mu \mathrm{m}$ ) of HDT island on (100) GaSb surface passivated in $2 \mathrm{mM} \mathrm{HDT}-$ $\mathrm{C}_{2} \mathrm{H}_{5} \mathrm{OH}$

range from $700 \times$ to $2100 \times$ and from $0.1 \mu \mathrm{m}$ to $0.3 \mu \mathrm{m}$, respectively. Using the $3 \mathrm{D}$ Rotary Head, the light aperture closed, coaxial illumination, high contrast system and special powerful software, qualitative and quantitative analysis could be made. Figures 8 presents the morphology and dimensions of the thiols structure. The images with the 3D profiles of thiols (Figs. 9-11) indicate that height of the largest thiols is even $3 \mu \mathrm{m}$.

Summarising, the 3D HIROX KH-8700 Digital Microscope was used for investigation of (100) GaSb surface treated by $2 \mathrm{mM}$ HDT- $\mathrm{C}_{2} \mathrm{H}_{5} \mathrm{OH}$ solution. The measurements were made quickly, non-destructively, and comprehensively. The various images have been obtained thanks the options offered in this system. There are shown the (100) GaSb surface with the thiols layer with the characteristic thiols islands.

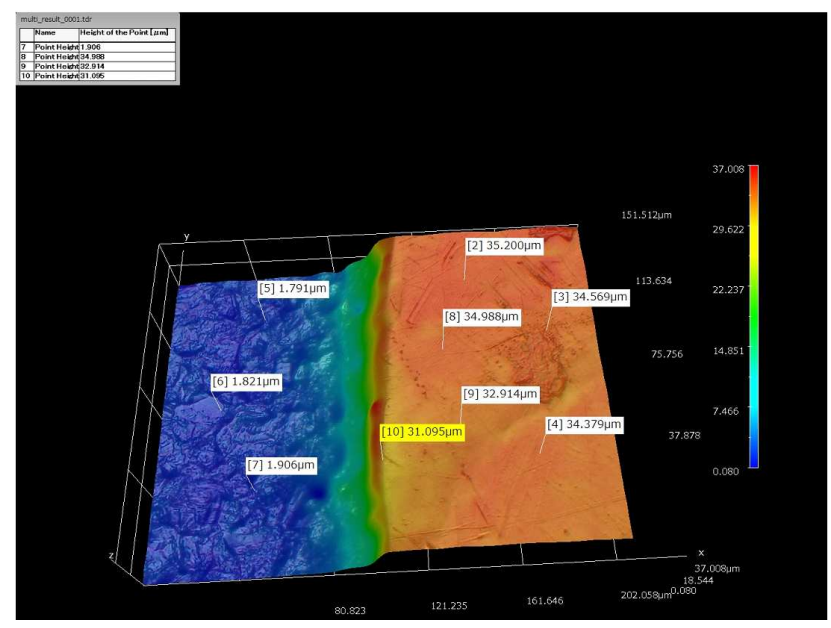

Fig. 11. Height measurement in 3D (point height) of HDT island on (100) GaSb surface passivated in $2 \mathrm{mM}$ $\mathrm{HDT}-\mathrm{C}_{2} \mathrm{H}_{5} \mathrm{OH}$.

\section{Acknowledgments}

This work was partially supported by the National Centre for Research and Development, Poland under project No. PBS1/B3/2/2012.

\section{References}

[1] E. Papis, A. Piotrowska, E. Kaminska, K. Golaszewska, R. Kruszka, T.T. Piotrowski, W. Rzodkiewicz, J. Szade, A. Winiarski, A. Wawro, Phys. Status Solidi C 4, 1448 (2007).

[2] O. Salihoglu, A. Muti, A. Aydinli, Proc. SPIE 8704, 87040T (2013).

[3] E. Plis, M.N. Kutty, S. Myers, A. Rathi, E.H. Aifer, I. Vurgaftman, S. Krishna, Infrared Phys. Technol. 55, 216 (2012).

[4] G. Wang, Y. Xu, L. Wang, Z. Ren, Z. He, J. Xing, Z. Niu, J. Phys. D, Appl. Phys. 45, 265103 (2012).

[5] J.J. Dubowski, O. Voznyy, G.M. Marshall, Appl. Surf. Sci. 256, 5714 (2010).

[6] O. Voznyy, J.J. Dubowski, Langmuir 24, 13299 (2008).

[7] M. Schvartzman, V. Sidorov, D. Ritter, Y. Paz, J. Vacuum Sci. Technol. B 21, 148 (2003).

[8] http://youtu.be/SopdETXE038. 